\title{
Australian Indigenous model of mental healthcare based on transdiagnostic cognitive-behavioural therapy co-designed with the Indigenous community: protocol for a randomised controlled trial - CORRIGENDUM
}

Maree Toombs, Bushra Nasir, Steve Kisely, Srinivas Kondalsamy-Chennakesavan, Leanne Hides, Neeraj Gill, Gavin Beccaria, Sharon Brennan-Olsen, Kaley Butten and Geoffrey Nicholson

\section{Copyright and usage}

(C) The Author(s) 2020. This is an Open Access article, distributed under the terms of the Creative Commons Attribution licence (http://creativecommons.org/licenses/by/4.0/), which permits unrestricted re-use, distribution, and reproduction in any medium, provided the original work is properly cited.

DOI: https://doi.org/10.1192/bjo.2020.16, Published online by Cambridge University Press, 06 April 2020

Keywords: CBT; transdiagnostic therapy; Indigenous; depressive disorders
This article originally referred to author Kaley Butten as 'Kayley Butten'. This was incorrect and we apologise for the error.

\section{Reference}

Toombs M, Nasir B, Kisely S, Kondalsamy-Chennakesavan S, Hides L, Gill N, Beccaria G, Brennan-Olsen S, Butten K and Nicholson G. (2020) Australian Indigenous model of mental healthcare based on transdiagnostic cognitive-behavioural therapy codesigned with the Indigenous community: protocol for a randomised controlled trial. Br J Open 2020; 6: e33. doi: 10.1192/bjo.2020.16. 